\title{
Effects of Changed School Entry Rules: Age Effects within Third Grade Students
}

\author{
Özgür Öner ${ }^{1}$, Öykü Çalışır ${ }^{2,3,4}$, Nazife Ayyıldız ${ }^{2,4,5}$, İpek Çelikağ ${ }^{2}$, Pınar Uran ${ }^{6}$, Sinan Olkun ${ }^{7 *}$ \\ Metehan Çiçek 2,4,8 \\ ${ }^{1}$ Bahçeşehir University, School of Medicine, Department of Child and Adolescent Psychiatry, Istanbul, TURKEY \\ ${ }^{2}$ Ankara University Brain Research Center, Ankara, TURKEY \\ ${ }^{3}$ Ankara University, Faculty of Educational Sciences, Psychological Counseling and Guidance Unit, Ankara, TURKEY \\ ${ }^{4}$ Ankara University Institute of Health Sciences, Department of Interdisciplinary Neuroscience, Ankara, TURKEY \\ ${ }^{5}$ Department of Mathematics Education, Institute of Educational Sciences, Ankara University, Ankara, TURKEY \\ ${ }^{6}$ Ankara University School of Medicine, Child and Adolescent Psychiatry Department, Ankara, TURKEY \\ ${ }^{7}$ TED University Department of Mathematics and Science Education, Ankara, TURKEY \\ ${ }^{8}$ Ankara University School of Medicine, Department of Physiology, Ankara, TURKEY
}

Received 15 November 2017 - Revised 5 February 2018 - Accepted 11 March 2018

\begin{abstract}
It has been reported that young age of school onset has important effects on academic and behavioral outcomes. Although there are studies using multinational data, data from low and middle income countries are few. As part of a larger study about mathematics learning difficulties, the aim of the present study was to evaluate the age of school entry on mathematics ability and general ability in standard tests and emotional and behavioral problems reported by their teachers among 2058 third grade students in Ankara, second biggest and capital city of Turkey. Results indicated lower mathematics and general abilities and higher hyperactivity/impulsivity, inattention and emotional problems scores as well as less prosocial behavior in the youngest group of children. Effect sizes were largest for general ability and mathematics ability. Our data were largely consistent with previous studies from other countries, and extended the literature by providing data from a middle income country.
\end{abstract}

Keywords: school entry, age effect, math achievement

\section{INTRODUCTION}

In Turkey, due to changes in law on school entry age (primary school, first grade), parents have faced a challenge as they had to make a decision. There is a graded system on school entry age: children older than 72 months are mandatory to enter school, children between 69-72 months may not enter school when parents provide a document from physicians indicating that the child is not ready for school, children between 66-68 months may not enter school when parents do not apply, children between 60-65 months may enter school if parents apply, and children who are younger than 59 months may not enter the first grade. This complex legal system leads to a mix of children with different ages in the same grade. Several parents applied to hospitals and clinics to have official medical documents indicating that their children are not eligible to enter school system, for they had concerns about their performance and adjustment at school.

Their concern is not without reason. Children who enter school one year later have $13 \%$ lower risk of repeating grade (Elder \& Lubotsky, 2009), and achieve better at school (Lien, Tambs, Oppedal, Heyerdahl, \& Bjertness, 2005). On the other hand, effect of schooling age on adult labor market performance seems not to be significant (Dobkin \& Ferreria, 2010). Using Trends in International Mathematics and Science Study (TIMSS) data, researchers showed

(C) 2018 by the authors; licensee Modestum Ltd., UK. This article is an open access article distributed under the terms and conditions of the Creative Commons Attribution License (http://creativecommons.org/licenses/by/4.0/).

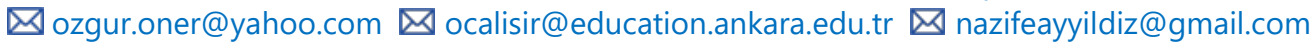
$\boldsymbol{\nabla}$ ipekcelikag@gmail.com $\boldsymbol{\Delta}$ pinaruran1@yahoo.com $\boldsymbol{\Delta}$ sinanolkun@gmail.com (*Correspondence) 


\section{Contribution of this paper to the literature}

- In many countries, the age is a very important variable in school entry. So it would be valuable to know if it makes any effect on students' academic and general achievements during the school years.

- It is also important to know the effect of dramatic changes in school entry rules.

- Findings on the effects of younger age of school entry on academic and behavioral outcomes are not clear. Although there are studies using multinational data, data from low and middle income countries are few. The present study evaluates the effects of age of school entry on mathematics ability and general ability in standard tests and emotional and behavioral problems reported by their teachers among third grade students.

that youngest students in fourth and eighth grades have significantly lower standardized test scores when compared with oldest students (Bedard \& Dhuey, 2006), indicating the longer run impact of relative age.

Effects of being younger-for-grade are not restricted to academic performance. Attention deficit hyperactivity disorder (ADHD) diagnosis is increased in younger children (Elder \& Lubotsky, 2009). Children born just under the cutoff date of kindergarten entry are less likely to be diagnosed ADHD and to be treated with a stimulant (Evans, Morrill \& Parente, 2010). Teacher reports are very important for ADHD diagnosis and teachers compare children with their peers. These findings call to attention the importance of relative standards in ADHD diagnosis (Elder, 2010).

Relatively younger age at school entry is also associated with higher risk of problems other than ADHD. Younger-for-grade students have been reported to be more likely classified as having learning disabilities (Dhuey \& Lipscomb, 2008; Gledhill, Ford, \& Goodman, 2002; Martin, Foels, Clanton, \& Moon, 2004). Muhlenweg (2010), based on data from 17 countries, showed that relatively younger students were are commonly victims of school violence. Another study reported higher rates of teenage pregnancy among younger school entrants (Black, Devereux, \& Salvanes, 2011). It has also been showed that children who entered school younger has a higher risk of being hyperactive at age 8 (but not age 11); at age 11 they were less adaptive to change. Those children who were relatively older at school entry has increased self-esteem years later (Thompson, Barnsley, \& Battle, 2004). In a large cross-sectional study, Goodman and associates reported that relatively younger children at school had higher scores at both teacher and parent reports; they were also at increased odds of having a psychiatric diagnosis. Authors commented that the results were consistent with "relative age" explanation rather than "season of birth" explanation (Goodman, Gledhill, \& Ford, 2003). However, early school entry did not have a significant impact on IQ (Mühlenweg, Blomeyer, Stichnoth \& Laucht, 2012).

On the other hand, previous literature is not totally conclusive. Morrison and colleagues (Morrison, Griffith, \& Alberts, 1997) found that relatively younger children made as much progress as older children at first grade. These children also made more progress than they would if they were in kindergarten. Several other studies reported no disadvantage of being younger for cohort in academic, behavioral or social terms (Buntaine \& Costenbander, 1997; De Meis \& Stearns, 1992; Jones \& Mandeville, 1990; McNamara, Scissons, \& Simonot, 2004). When the other side of the coin is examined, delayed entry to school may also lead to both positive and negative results. Taken together, most of the studies showed that delayed entry to school has "no, little, negative or diminishing effects" (Martin, 2009).

Therefore, effects of younger age of school entry on academic and behavioral outcomes are not clear. Although there are studies using multinational data, data from low and middle income countries are few. The aim of the present study was to evaluate age of school entry on mathematics ability and general ability in standard tests and emotional and behavioral problems reported by their teachers among third grade students in Ankara, second biggest and the capital city of Turkey.

In sum, we collected data from third grade students by using general ability and mathematics ability tests and teacher questionnaires. We divided the sample into three groups based on their age of school entry (early entrants, correct age for entry and late entrants). We investigated the effect of the age of school entry on mathematics performance and some behavioral measures by taking into account the socioeconomic status, general ability and teacher reports about the students.

\section{METHODS}

\section{Sample}

Sample was part of a study on dyscalculia in third grade students. The parent study has three stages: screening, dyscalculia assessment and functional magnetic resonance imaging. For the first stage, 13 primary state schools at Ankara center were selected to represent lower, medium and higher socioeconomic backgrounds. At the screening 
phase, all students at the third grade from the selected schools were included. 2058 third grade student from these schools were screened with general ability (Raven's Standard Progressive Matrices) and mathematics ability tests (Mathematics Achievement Test and Calculation Performance Test) and screening questionnaires filled by their teachers (Swanson, Nolan, and Pelham -IV Questionnaire and Strengths and Difficulties Questionnaire). Data collected from 143 subjects were incomplete; therefore, 1915 subjects were included in data analysis. Raven's test and mathematics achievement tests were conducted by trained researchers in two separate sessions. Ankara University Internal Review Board approved the study.

\section{Measurements}

Swanson, Nolan, and Pelham -IV Questionnaire (SNAP-IV): Items include 18 ADHD symptoms, 9 in each hyperactivity/impulsivity and inattention subscales. Items are rated on 4 point scale from (0) not at all to (3) very much. Average rating per item (ARI) subscale score is calculated by adding all points in the subscale and dividing it by 9. SNAP-IV is reported to be a reliable and valid instrument (Bussing et al., 2008). In our study, teachers completed the SNAP-IV.

Strengths and Difficulties Questionnaire (SDQ, Goodman et al, 2001): SDQ gets information on 25 attributes, which are divided into 5 scales: emotional symptoms, conduct problems, hyperactivity-inattention, peer problems and prosocial behaviors. Extended forms include an impact supplement which provides information on whether the respondent thinks that the child has a problem and the impact of the problem in terms of social impairment, burden, chronicity and overall distress. SDQ has satisfactory reliability and validity (Goodman, 2001). Turkish form is also reported to be valid and reliable (Güvenir et al., 2008). We used SDQ Teacher form in the study.

Raven Progressive Matrices (RPM): We used Standard Progressive Matrices (SPM). SPM includes 5 sets of a total of 60 diagramatic puzzles with increasing difficulty. Test has been reported to have good reliability and validity (Raven, 2000).

Mathematics Achievement Test (MAT, Fidan, 2013): It includes counting, number patterns and basic calculation, and based on Turkish Ministry of Education mathematics curriculum. It takes almost 45 minutes to complete the test. Cronbach alpha coefficient is 0.93 for third grade.

Calculation Performance Test (De Vos, 1992; Olkun, Can, \& Yeşilpınar, 2013): The test consists of 5 columns of arithmetic calculations (subtraction, multiplication, division, addition and mixed). One minute is allowed for each column and total correct answers are taken into account.

Data Analysis: Based on age of school entry, the sample was divided into three groups: early entrants (age of entry: 61-65 months, $n=89$ ), correct age for entry (age of entry: 66-77 months, $n=1337$ ), late entrants (age of entry: $>78$ months, $n=464$ ). Socioeconomic status (based on school district, low: $n=837$, middle: $n=1078$ ), gender (male: 947, 49.5\%), Raven's SPM scores were other independent factors. Data on Kindergarten attendance was obtained from 1565 subjects, and was included in separate analysis and reported only when different from the main analysis. First, in univariate analysis of variance (ANOVA), we investigated the effects of each independent variable on mathematics achievement tests, SNAP-IV Hyperactivity/Impulsivity and Inattention ARI scores, SDQ Total Problems and Prosocial Behaviors scores. Second, we used logistic regression analysis to investigate the relative effects of the independent variables. In these models, Raven SPM score, age of school onset group, socioeconomic status (SES), and gender were independent factors. Analysis were performed separately for each outcome. Outcomes were defined as being in the lowest 10th percentile for MAT, CPT, SDQ Prosocial Behaviors scores, or in the higher 10th percentile for SDQ Total Problems, SNAP-IV Hyperactivity/Impulsivity and Inattention ARI scores. In the binary logistic regression analysis, the outcomes were coded as 1 and other cases were coded as 0 . Values of $\mathrm{p}<.05$ were reported as statistically significant.

\section{RESULTS}

Age groups: MAT, CPT and SPM were available for 1904, 1900 and 1898 students, respectively. SDQ and SNAPIV were available for 1621 and 1580 students, respectively. Current age range of the sample was 87 to 123 months. Girl to boy ratio was not statistically significant between age groups, $\left.x^{2}(1, N=1904)=1.8, p=0.4\right)$.

\section{Univariate Effects of Independent Variables on Mathematics Ability and Teacher Ratings}

1- Age of school entry: Descriptives were summarized in Table 1. Results indicated that mathematics ability, $F(2,1883)=23.7 ; p<.001$, general ability $F(2,1879)=21.4 ; p<.001$, and prosocial behaviors $F(2,1630)=6.2 ; p=.002$, increased significantly with age of school entry among third grade students. On the other hand, SDQ Total Problems score $F(2,1651)=4.4 ; p=.01$, and SNAP-IV based attention problems $F(2,1604)=14.4 ; p<.001$, and hyperactivity/impulsivity $F(2,1604)=7.0 ; p<.001)$, decreased with age of school entry. However, all effect sizes were very small $\left(\eta^{2}\right.$ between 0.006 and 0.025$)$. 
Table 1. Comparisons among the groups based on the age of school entry

\begin{tabular}{lccccc}
\hline & \multicolumn{3}{c}{ Age of School Entry } & \multicolumn{2}{c}{ Significance } \\
\hline & Early Entrants & Correct-for-age & Late Entrants & $\boldsymbol{F} ; \boldsymbol{p}$ & $\boldsymbol{\eta}^{\mathbf{2}}$ \\
\hline Gender (male \%) & $44.9 \%$ & $50.5 \%$ & $47.8 \%$ & & \\
\hline MAT & $6.4 \pm 4.0$ & $8.8 \pm 4.1$ & $9.6 \pm 4.1$ & $23.7 ;<.001$ & .025 \\
\hline SNAP-4 Inattention & $66.0 \pm 25.3$ & $77.8 \pm 25.9$ & $82.6 \pm 24.5$ & $17.2 ;<.001$ & .018 \\
\hline SNAP-4 Hyperactivity & $.72 \pm .81$ & $.55 \pm .73$ & $.36 \pm .60$ & $14.4 ;<.001$ & .018 \\
\hline SDQ Total & $.59 \pm .85$ & $.40 \pm .65$ & $.31 \pm .58$ & $7.0 ; .001$ & .009 \\
\hline
\end{tabular}

MAT: Mathematics Achievement Test, CPT: Calculation Performance Test, SNAP-4: Strengths and Difficulties scores

2- Gender: Gender was a factor for mathematics ability, emotional and behavioral measures. Results indicated that girls had higher MAT $F(1,1904)=7.1 ; p=.008$, SPM general ability $F(1,1904)=12.0 ; p=.001$, and prosocial behaviors scores $F(1,1651)=13.9 ; p<.001$. On the other hand, SDQ Total Problems score $F(1,1651)=8.4 ; p=.004$, SNAP-IV Inattention ARI $F(1,1625)=39.7 ; p<.001$, and Hyperactivity/Impulsivity ARI $F(1,1625)=80.1 ; p=.001$, were higher in boys. All effect sizes were very small ( $\eta 2$ between 0.004 and 0.047$)$.

3- SES: Results indicated that MAT $F(1,1904)=9.9 ; p=.002, \operatorname{CPT} F(1,1904)=23.7 ; p<.001$, SPM general ability $F(1,1904)=11.7 ; p=.001$, and prosocial behaviors $F(1,1651)=13.9 ; p<.001$, were higher in higher SES group. On the other hand, SNAP-IV based attention problems $F(1,1625)=15.2 ; p<.001$, and hyperactivity/impulsivity $F(1,1625)$ $=10.2 ; \mathrm{p}=.001$, decreased with SES. All effect sizes were very small $(\eta 2$ between 0.006 and 0.009$)$.

4- General Ability: General ability had a significant and larger effect on all variables. MAT $F(1,1904)=961.4$; $p<.001, \eta^{2}=.34$, CPT $\left.F(1,1904)=551.0 ; p<.001, \eta^{2}=.23\right)$, and prosocial behaviors scores $F(1,1651)=69.9 ; p<.001$, $\left.\eta^{2}=.04\right)$ increased with higher general ability, measured by Raven SPM. On the other hand, SDQ Total Problems score $\left.F(1,1651)=41.2 ; p<.001, \eta^{2}=.03\right)$, SNAP-IV Inattention ARI $\left.F(1,1625)=190.6 ; p<.001, \eta^{2}=.11\right)$, and Hyperactivity/Impulsivity ARI $\left.F(1,1625)=57.9 ; p=.001, \eta^{2}=.04\right)$, were higher in children with lower general ability.

5- Kindergarten: MAT $F(1,1583)=29.6 ; p<.001, \operatorname{CPT} F(1,1583)=17.0 ; p<.001$, SPM general ability $F(1,1583)=$ 42.3; $p<.001$, and prosocial behaviors $F(1,1353)=10.0 ; p=.002$, were higher in children who attended Kindergarten. On the other hand, SNAP-IV based attention problems $F(1,1335)=4.7 ; p=.030$ ) were lower among these children. Effect sizes were between 0.004 and 0.026 .

\section{Lowest Mathematics Ability and Prosocial Behaviors and Highest Problem Groups}

1- Age of school entry: There was a "dose-response" effect between age of school entry and rates of having MAT (early: $27.0 \%$; on-time: $13.0 \%$; late: $9.9 \%$ ) and CPT scores (early: $23.6 \%$; on-time: $10.3 \%$; late: $6.9 \%$ ) lower than 10th percentile. Late entrants have lower rate of SDQ Prosocial Behaviors (early: $13.9 \%$; on-time: 14.7\%; late: $7.9 \%$ ) score lower than 10th percentile. On the other hand, children who entered school earlier also had higher rates of having SNAP-IV Inattention (early: $21.3 \%$; on-time: $12.1 \%$; late: $8.0 \%$ ) and Hyperactivity/Impulsivity ARI (early: 18.8\%; on-time: $11.3 \%$; late: $6.5 \%$ ), and SDQ Total Problems (early: $16.0 \%$; on-time: $13.5 \%$; late: $8.3 \%$ ) scores over 90th percentile when compared with other students.

2- Gender: Rate of boys was significantly higher than girls (14.9\% vs 11.2\%) for having MAT score and SDQ Prosocial Behaviors score $(16.8 \%$ vs $9.1 \%)$ lower than 10 th percentile. Boys also had higher rates of having SNAPIV Inattention (17.2\% vs 6.0\%) and Hyperactivity/Impulsivity ARI (14.5\% vs 6.3\%), and SDQ Total Problems (14.7\% vs $10.0 \%$ ) scores over 90 th percentile when compared with girls.

3- SES: Children from lower SES background had significantly higher rates of having SDQ Prosocial Behaviors score $(17.4 \%$ vs $9.3 \%)$ lower than 10 th percentile. These children also had higher rates of having SNAP-IV Inattention (13.5\% vs 7.9\%) and Hyperactivity/Impulsivity ARI (14.2\% vs 9.3\%), scores over 90th percentile when compared with children from higher SES.

4- Kindergarten: Children who did not attend to Kindergarten had higher rates of MAT (19.7\% vs $9.4 \%)$, and CBT (15.4\% vs $8.1 \%)$ lower than 10th percentile. These children also had higher rates of having SDQ Total Problems $(14.1 \%$ vs $9.9 \%)$ scores over 90 th percentile when compared with other children.

\section{MULTIVARIATE MODELS}

\section{Mathematics Ability}

Logistic regression analysis indicated that being in the lowest 10th percentile for MBT performance was associated with lower Raven SPM score (See Table 2 and 3 for details). On the other hand, being in the lowest $10^{\text {th }}$ percentile for CPT score was associated with Raven SPM score and younger age of school entry. 
Table 2. Results of the logistic regression analysis

\begin{tabular}{|c|c|c|c|c|c|c|c|c|c|c|}
\hline & \multicolumn{5}{|c|}{ MAT } & \multicolumn{5}{|c|}{ CPT } \\
\hline & B & SE & Wald & $\mathbf{p}$ & OR (95\%CI) & B & SE & Wald & $\mathbf{P}$ & OR $(95 \% \mathrm{CI})$ \\
\hline Gender & .17 & .16 & 1.2 & .28 & $1.2(.87-1.6)$ & -.17 & .17 & .96 & .33 & $.85(.61-1.2)$ \\
\hline Age of school entry & 3.1 & & & .22 & & 5.1 & & & .078 & \\
\hline Correct for age & -.40 & .28 & 1.9 & .16 & $67.2(.39-1.2)$ & -.46 & .29 & 2.4 & .12 & $.63(.35-1.1)$ \\
\hline Late entry & -.56 & .32 & 3.1 & .08 & $.57(.30-1.1)$ & -.77 & .34 & 5.1 & .02 & $.46(.23-.91)$ \\
\hline RSPM & -.14 & .01 & 227.8 & $<.001$ & $.87(.85-.88)$ & -.14 & .01 & 188.4 & $<.001$ & $.87(.85-.89)$ \\
\hline SES & -13 & .16 & .73 & .39 & $.88(.65-1.2)$ & -15 & .17 & .79 & .38 & $.886(.62-1.2)$ \\
\hline
\end{tabular}

${ }^{*}$ RSPM score, age of school onset group, socioeconomic status (SES), and gender were independent factors.

**Outcomes were defined as being in the lowest 10th percentile for MAT, CPT, SDQ Prosocial Behaviors scores, or in the higher 10th percentile for SDQ Total Problems, SNAP-IV Hyperactivity/Impulsivity and Inattention ARI scores.

${ }^{* * *} \mathrm{Cl}$ : Confidence Interval.

Table 3. Results of the logistic regression analysis (continuing from Table 2)

\begin{tabular}{|c|c|c|c|c|c|c|c|c|c|c|c|c|c|c|c|}
\hline & \multicolumn{5}{|c|}{ SNAP-4 Inattention } & \multicolumn{5}{|c|}{ SNAP-4 Hyperactivity } & \multicolumn{5}{|c|}{ SDQ Total } \\
\hline & B & SE & Wald & $\mathbf{p}$ & $\begin{array}{c}\text { OR } \\
(95 \% \mathrm{Cl}) \\
\end{array}$ & B & SE & Wald & $\mathbf{P}$ & $\begin{array}{c}\text { OR } \\
(95 \% \mathrm{Cl}) \\
\end{array}$ & B & SE & Wald & $\mathbf{P}$ & $\begin{array}{c}\text { OR } \\
(95 \% \mathrm{Cl}) \\
\end{array}$ \\
\hline Gender & .87 & .18 & 22.6 & $<.001$ & $\begin{array}{c}2.3 \\
(1.7-3.4) \\
\end{array}$ & 1.2 & .18 & 41.9 & $<.001$ & $\begin{array}{c}3.2 \\
(2.2-4.5) \\
\end{array}$ & .36 & .16 & 5.0 & .025 & $\begin{array}{c}1.4 \\
(1.1-2.0) \\
\end{array}$ \\
\hline $\begin{array}{l}\text { Age of } \\
\text { school entry }\end{array}$ & 7.1 & & & .029 & & 7.6 & & & .022 & & 5.1 & & & .078 & \\
\hline $\begin{array}{l}\text { Correct for } \\
\text { age }\end{array}$ & -25 & .32 & .61 & .43 & $\begin{array}{c}.78 \\
(.42-1.5) \\
\end{array}$ & -.53 & .30 & 3.1 & .08 & $\begin{array}{c}.59 \\
(.33-1.1) \\
\end{array}$ & .02 & .34 & .002 & .96 & $\begin{array}{c}1.0 \\
(.53-2.0) \\
\end{array}$ \\
\hline Late entry & -.82 & .37 & 4.8 & .03 & $\begin{array}{c}.44 \\
(.21-.92) \\
\end{array}$ & -.93 & .35 & 7.2 & .007 & $\begin{array}{c}.40 \\
(.20-.78) \\
\end{array}$ & -.45 & .38 & 1.5 & .23 & $\begin{array}{c}.64 \\
(.31-1.3) \\
\end{array}$ \\
\hline RSPM & -.08 & .01 & 71.8 & $<.001$ & $\begin{array}{c}.92 \\
(.91-.94)\end{array}$ & -.04 & .01 & 22.5 & $<.001$ & $\begin{array}{c}.96 \\
(.94-.98)\end{array}$ & -.05 & .01 & 37.8 & $<.001$ & $\begin{array}{c}.95 \\
(.93-.97)\end{array}$ \\
\hline SES & -.49 & .17 & 8.0 & .005 & $\begin{array}{c}.61 \\
(.44-.86)\end{array}$ & -.40 & .16 & 6.2 & .013 & $\begin{array}{c}.67 \\
(.49-.92)\end{array}$ & .35 & .16 & 4.8 & .028 & $\begin{array}{c}1.4 \\
(1.0-1.9) \\
\end{array}$ \\
\hline
\end{tabular}

${ }^{*}$ RSPM score, age of school onset group, socioeconomic status (SES), and gender were independent factors.

${ }^{* *}$ Outcomes were defined as being in the lowest 10th percentile for MAT, CPT, SDQ Prosocial Behaviors scores, or in the higher 10th percentile for SDQ Total Problems, SNAP-IV Hyperactivity/Impulsivity and Inattention ARI scores.

${ }^{* * *} \mathrm{Cl}$ : Confidence Interval.

\section{Teacher Ratings}

Being male, having lower Raven SPM score, lower SES and younger age of school entry were all associated with increased risk of being in the lowest 10th percentile for prosocial behaviors, and 90th percentile of SDQ Total Problems score, and SNAP-IV Inattentiveness and Hyperactivity/Impulsivity ARI. Overall, results suggested that, female students and students with better general ability had better prosocial skills and lower behavioral problems. Students with older age of school entry had less attention problems, hyperactivity and impulsivity.

\section{DISCUSSION}

Our results indicated that there were several significant age related differences among students in the same grade. These differences included lower mathematics in the youngest group of children in third grade when compared with particularly oldest group of children in the same grade. Also youngest children showed lower general abilities and higher SNAP-IV hyperactivity/impulsivity, SNAP-IV inattention and SDQ emotional problems score as well as less prosocial behavior than oldest ones. This was consistent with a previous study which used parent and teacher rated SDQ to compare relative age effects and reported higher total problem scores in younger children (Goodman et al., 2003). Mean age difference between youngest and oldest group in the analysis was almost 16 months. Effect sizes of differences of means between the youngest and oldest age groups were largest for general ability and mathematics ability. Effect sizes for behavioral measures were smaller; largest difference was in SNAP-IV Inattention score. Smaller effect sizes were detected for SDQ Emotion Problems and Prosocial Behaviors, and SNAP-IV Hyperactivity/Impulsivity. Gender was another important factor, particularly for Hyperactivity/Impulsivity, Inattention and Conduct Problems. This was consistent with previous studies which reported higher prevalence of these problems in males (NICE ADHD Guideline, 2008). Effect size of gender on mathematics and general abilities were small. 
Results suggested that, when compared with the oldest group, youngest students were less mature in cognitive and behavioral terms. Attention problems were associated with both general ability and mathematics ability ( $\mathrm{r}=-$ .33 and -.40 , respectively). There were at least three possible explanations, which were not mutually exclusive, of this association. First, this association might be spurious. It can be speculated that, attention problems reported by teachers might be influenced by academic performance, which was lower in younger students, as indicated by worse mathematics ability. It has been reported that teacher reports may be based on comparison of children with their peers (Evans et al., 2010). Older, and more cognitively mature, children had higher mathematics ability and more prosocial behaviors. This may lead to a less favorable assessment of younger children by the teachers. In fact, it has been suggested that, children who were just under the cut-off age for school entry, who are older, had lower rate of ADHD and stimulant treatment (Evans et al., 2010). Second, children with lower general (lower SPM score) or mathematics ability might have more prominent attention problems and hyperactivity/impulsivity. It is well known that attention problems and hyperactivity/impulsivity is more common in subjects with learning problems (NICE ADHD Guideline, 2008). Third, subjects with attention problems might have lower academic performance, which has also been reported extensively (e.g. Wolraich et al., 2003).

Our results were consistent with previous studies. It has been shown that youngest children in a given grade had lower standardized test scores when compared with oldest students (Bedard \& Dhuey, 2006), and children who enter school early had a higher risk of repeating grade (Elder \& Lubotsky, 2009), and achieve less at school (Lien et al., 2005). Younger children also have a higher risk of receiving ADHD diagnosis (Elder \& Lubotsky, 2009), being victim to bullying (Muhlenweg, 2010), and having learning disabilities (Dhuey \& Lipscomb, 2008; Martin et al., 2004). In our sample, due to regulatory changes, age range was over one year in third grade. This was larger than most of the previous studies. Multiplier processes are important in amplifying differences. In fact, younger children in school were reported to have higher risk of psychopathology in adolescence, much later than school entry (Goodman et al., 2003). From an academic stand-point, older students' maturity advantage may increase their chance of selection for advanced curriculum groups or faster progress in a common curriculum, leading to accumulation of more skills (Bedard \& Dhuey, 2006). Gender, socioeconomic status, race and other factors may also show multiplying effects. These processes may even be more evident in Turkey, where high-school and college entries depend on success in centrally administered examinations. In high-school exams, students are compared to their same grade peers, and there are huge quality differences between high-schools, which will further increase academic differences.

Limitations of the study included lack of a valid and reliable socioeconomic status indicator, lack of parent reports, assessment of only general and mathematics abilities. In Turkey, during the first four grades, teachers are responsible for a single classroom. We collected data at April, near end of the spring term. Therefore, we believe that teachers had ample opportunity to have valid and reliable opinions about their students. On the other hand, Elder reported that (2010), age of school entry affected teachers' perceptions of whether the child exhibits ADHDrelated symptoms more strongly than parental perceptions. Therefore, parent reports might not show the age effects we reported.

We reported in this article data from a low-middle income country, which included academic and behavioral variables obtained from a single sample. Although academic variables have been reported more extensively in multinational studies, behavioral data are more sparse. Our data were largely consistent with previous studies from other countries, and extended the literature by showing evidence related to the differences in a single school grade. The data indicated that younger children in the same school grade showed lower general and mathematical ability and higher ADHD symptom scores based on teachers' evaluations.

\section{ACKNOWLEDGEMENT}

This Project has been funded by the Scientific and Technological Research Council of Turkey (TUBITAK) under the grant number 214-S-069 in 2015.

\section{REFERENCES}

Bedard, K., \& Dhuey, E. (2006). The persistence of early childhood maturity: international evidence of long-run age effects. Quarterly Journal of Economics, 121, 1437-1472. https://doi.org/10.1093/qje/121.4.1437

Black, S. E., Devereux, P. J., \& Salvanes, K. G. (2011). Too young to leave the nest? The effects of school starting age. The Review of Economics and Statistics, 93, 455-467. https:/ / doi.org/10.1162/REST_a_00081

Buntaine, R. L., \& Costenbader, V. K. (1997). The effectiveness of a transitional prekindergarten program on later academic achievement. Psychology in the Schools, 34(1), 41-50. https://doi.org/10.1002/(SICI)15206807(199701)34:1<41::AID-PITS5>3.0.CO;2-Y 
Bussing, R., Fernandez, M., Harwood, M., Wei, H., Garvan, C. W., Eyberg, S. M., \& Swanson, J. M. (2008). Parent and teacher SNAP-IV ratings of attention deficit hyperactivity disorder symptoms: psychometric properties and normative ratings from a school district sample. Assessment, 15, 317-328. https:// doi.org/10.1177/1073191107313888

De Meis, J. L., \& Stearns, E. S. (1992). Relationship of school entrance age to academic and social performance. The Journal of Educational Research, 86(1), 20-27. https:/ / doi.org/10.1080/00220671.1992.9941823

De Vos, T. (1992). Tempo-test rekenen (Number fact retrieval test). Nijmegen: Berkhout.

Dhuey, E., \& Lipscomb, S. (2008). What makes a leader? Relative age and high school leadership. Economics of Education Review, 27, 173-183. https:/ / doi.org/10.1016/j.econedurev.2006.08.005

Dobkin, C., \& Ferreira, F. (2010). Do school entry laws affect educational attainment and labor market outcomes? Economics of Education Review, 29, 40-54. https://doi.org/10.1016/j.econedurev.2009.04.003

Elder, T. E. (2010). The Importance of Relative Standards in ADHD Diagnoses: Evidence Based on Exact Birth Dates. Journal of Health Economics, 29, 641-656. https:/ / doi.org/10.1016/j.jhealeco.2010.06.003

Elder, T. E., \& Lubotsky, D. H. (2009). Kindergarten Entrance Age and Children's Achievement: Impacts of State Policies, Family Background, and Peers. Journal of Human Resources, 44, 641-683. https:// doi.org/10.1353/jhr.2009.0015

Evans, W. M., Morrill, M. S., \& Parente, S. T. (2010). Measuring inappropriate medical diagnosis and treatment in survey data:The case of ADHD among school-age children. Journal of Health Economics, 29, 657-673. https://doi.org/10.1016/j.jhealeco.2010.07.005

Fidan, E. (2013). İlkokul Öğrencileri İçin Matematik Dersi Sayılar Öğrenme Alanında Başarı Testi Geliştirilmesi [Mathematics Achievement Test for Primary School Students] (Unpublished masters' thesis), Ankara Üniversitesi, Eğitim Bilimleri Enstitüsü.

Gledhill, J., Ford, T., \& Goodman, R. (2002). Does season of birth matter? The relationship between age within the school year (season of birth) and educational difficulties amongst a representative general population sample of children and adolescents (aged 5-15) in Great Britain. Research in Education 68, 41-47. https:/ / doi.org/10.7227/RIE.68.4

Goodman, R. (2001). Psychometric properties of the strengths and difficulties questionnaire (SDQ). Journal of American Academy of Child and Adolescent Psychiatry, 40, 1337-1345. https://doi.org/10.1097/00004583200111000-00015

Goodman, R., Gledhill, J., \& Ford, T. (2003). Child psychiatric disorder and relative age within school year: cross sectional survey of large population sample. British Medical Journal, 327, 472-475. https:// doi.org/10.1136/bmj.327.7413.472

Güvenir, T., Özbek, A., Baykara, B., Arkar, H., Şentürk, B., \& İncekaş, S. (2008). Psychometric Properties of The Turkish Version of The Strengths and Difficulties Questionnaire (SDQ). Turkish Journal of Child Adolescent Mental Health, 15, 65-74. Retrieved from http://toad.edam.com.tr/sites/default/files/pdf/gucler-veguclukler-anketi-toad.pdf

Jones, M. M., \& Mandeville, G. K. (1990). The effect of age at school entry on reading achievement scores among South Carolina students. Remedial and Special Education, 11(2), 56-62. https:/ / doi.org/10.1177/074193259001100209

Lien, L., Tambs, K., Oppedal, B., Heyerdahl, S., \& Bjertness, E. (2005). Is relatively young age within a school year a risk factor for mental health problems and poor school performance? A population-based cross-sectional study of adolescents in Oslo, Norway. BMC Public Health 5, 102. https:/ / doi.org/10.1186/1471-2458-5-102

Martin, A. J. (2009). Age appropriateness and motivation, engagement, and performance in high school: Effects of age within cohort, grade retention, and delayed school entry. Journal of Educational Psychology, 101(1), 101114. https://doi.org/10.1037/a0013100

Martin, R. P., Foels, P., Clanton, G., \& Moon, K. (2004). Season of birth is related to child retention rates, achievement, and rate of diagnosis of specific ld. Journal of Learning Disabilities, 37, 309-317. https:/ / doi.org/10.1177/00222194040370040301

McNamara, J., Scissons, M., \& Simonot, S. (2004). Should We "Redshirt" in Kindergarten? A Study of the Effect of Age on Kindergarteners' Reading Readiness. Alberta Journal of Educational Research, 50(2). Retrieved from http:/ / ajer.journalhosting.ucalgary.ca/index.php/ajer/article/view/449

Morrison, F. J., Alberts, D. M., \& Griffith, E. M. (1997). Nature -nurture in the classroom: Entrance age, school readiness, and learning in children. Developmental Psychology, 33(2), 254. http://dx.doi.org/10.1037/00121649.33.2.254 
Mühlenweg, A. M. (2010). Young and innocent: International evidence on age effects within grades on victimization in elementary school. Economics Letters, 109, 157-160. https:/ / doi.org/10.1016/j.econlet.2010.08.032

Mühlenweg, A., Blomeyer, D., Stichnoth, H., \& Laucht, M. (2012). Effects of age at school entry (ASE) on the development of non-cognitive skills: Evidence from psychometric data. Economics of Education Review, 31, 68-76. https:/ / doi.org/10.1016/j.econedurev.2012.02.004

National Institute for Health and Clinical Excellence. (2008). Attention deficit hyperactivity disorder: diagnosis and management of ADHD in children, young people and adults. (Clinical guideline 72). Retrieved from http://www.nice.org.uk/CG72

Olkun, S., Can, D., \& Yeşilpınar, M. (2013). Hesaplama Performansı Testi: Geçerlilik ve Güvenilirlik Çalışması. XII. Ulusal Sınıf Öğretmenliği Sempozyumu Bildiriler Kitabı. Aydın: Adnan Menderes Üniversitesi, 89-92. [Reliability and Validity Study of the Computational Performance Test]. In Procedings of the XII. National Classroom Teacher Education Symposium held in Aydın University: Aydın.

Raven, J. (2000). The Raven's progressive matrices: change and stability over culture and time. Cognitive Psychology, 41, 1-48. https:/ / doi.org/10.1006/cogp.1999.0735

Thompson, A. H., Barnsley, R. H., \& Battle, J. (2004). The relative age effect and the development of self-esteem. Educational Research, 46(3), 313-320. https:/ / doi.org/10.1080/0013188042000277368

Wolraich, M., Lambert, E., Baumgaertel, A., Garcia-Tornel, S., Feurer, I. D., Bickman, L., \& Doffing, M. A. (2003). Teachers' screening for attention deficit/hyperactivity disorder: comparing multinational samples on teacher ratings of ADHD. Journal of Abnormal Child Psychology, 31, 445-455. https:/ / doi.org/10.1023/A:1023847719796

\section{http://www.ejmste.com}

